\title{
O Egito em tempo de revolução. As lutas dos trabalhadores antes e depois das revoltas de 2011
}

Egypt in the Revolutionary Age Workers' struggles before and after the 2011 uprisings

L'Égypte en temps de révolution. Les luttes des travailleurs avant et après les révoltes de 2011

Iside Gjergji

Tradutor. João Paulo Moreira

\section{(2) OpenEdition}

\section{Journals}

Edição electrónica

URL: http://journals.openedition.org/rccs/5544

DOI: $10.4000 /$ rccs. 5544

ISSN: 2182-7435

\section{Editora}

Centro de Estudos Sociais da Universidade de Coimbra

\section{Edição impressa}

Data de publição: 1 Maio 2014

Paginação: 81-110

ISSN: 0254-1106

\section{Refêrencia eletrónica}

Iside Gjergji, « O Egito em tempo de revolução. As lutas dos trabalhadores antes e depois das revoltas de 2011 », Revista Crítica de Ciências Sociais [Online], 103 | 2014, colocado online no dia 26 maio 2014 criado a 30 abril 2019. URL : http://journals.openedition.org/rccs/5544; DOI : 10.4000/rccs.5544 


\section{ISIDE GJERGJI}

\section{O Egito em tempo de revolução. As lutas dos trabalhadores antes e depois das revoltas de 2011}

Os comentaristas ocidentais chamaram à revolução egípcia uma revolução-Facebook, ou seja, um fenómeno sociopolítico instigado (sobretudo através das redes sociais) essencialmente por jovens da classe média e com um nível elevado de instrução, que reivindicavam reformas democráticas de tipo ocidental. Desta imagem de postal ilustrado falsamente revolucionário foram apagadas as raízes socioeconómicas da revolta egípcia de 2011 . Consequentemente, fica quase a ideia de que a inaudita vaga de protestos de natureza laboral dos últimos três anos terá surgido do nada, dando-se por isso pouca atenção ao papel dos trabalhadores no levantamento de 2011 . O presente artigo sustenta que no cerne da revolta egípcia estão fatores socioeconómicos, e nessa perspetiva ele pretende contribuir com alguns passos fundamentais no sentido de se considerar que o crescente movimento operário egípcio é um elemento primacial do processo revolucionário a longo prazo.

Palavras-chave: Egito; movimento operário; processo revolucionário; redes sociais; revolução.

Se o povo quiser, um dia, vir a ter vida, decerto o destino lhe há de conceder tal desejo. As suas grilhetas hão de quebrar-se e a sua noite há de decerto dissipar-se. ${ }^{1}$

\section{Introdução}

Segundo um retrato muito frequentemente ouvido nos debates jornalísticos e académicos ocidentais sobre a revolta em massa ocorrida no Egito em 2011,

\footnotetext{
${ }^{1}$ Estes versos do poeta tunisino Abul-Qacem Al-Shebbi, que inspiraram a mais famosa das proclamações dos protestos árabes ("O povo quer ... a queda do regime”), traduziram de forma perfeita os desejos e reivindicações do povo árabe expressos nas revoltas de 2011. "O povo quer..." é eco que ainda se ouve nas ruas árabes.
} 
o que se passou foi que jovens utilizadores do Twitter e do Facebook teriam conseguido, através do uso das redes sociais, mobilizar e organizar com enorme rapidez milhões de manifestantes. A agitação vivida no Egito tem sido, assim, muitas vezes interpretada como sendo um fenómeno de natureza sociopolítica, essencialmente instigado por jovens da classe média com um nível elevado de instrução e desempregados (Acedo, 2011; Bottazzi e Hamaui, 2011). Nesta visão dos acontecimentos, o movimento operário e a sua luta de décadas recebem escassa atenção, sendo relegados, a priori, para um papel irrelevante. Porém os protestos sem precedentes dos trabalhadores egípcios desde 2006 apontam para o papel crucial dos movimentos operários nas transformações em curso, tanto no plano da política como no plano dos valores.

O presente artigo pretende dar alguns contributos essenciais no sentido de se considerar que a revolta egípcia de 2011 foi um processo histórico complexo, em que o movimento operário assumiu uma grande importância. A visão proposta poderá abalar a opinião convencional que no Ocidente se encontra em relação aos países árabes - Egito incluído -, segundo a qual se trata de uma realidade "moldada pelo 'Islão', [... . com uma forte componente antiocidental e antimoderna (ou simplesmente do tipo 'eles odeiam-nos'), e singularmente suscetível ao radicalismo político irracional, ao autoritarismo e ao terrorismo" (Beinin e Vairel, 2011a: 1). Esta representação grotesca e diabolizadora do Islão já vem de há muito. Ela assenta numa longa história de conflitos culturais e materiais entre o 'mundo cristão' e o 'mundo islâmico', que importa não discutir de uma maneira abstrata. Poderia, com efeito, ser de grande utilidade reconstituir na totalidade a história dessas relações e da sua evolução ao longo dos tempos, evidenciando assim, para além dos já bem conhecidos conflitos violentos, as trocas e as influências recíprocas registadas entre a 'civilização europeia' e a 'civilização islâmica'. Mas o presente artigo, como já ficou dito, propõe-se uma tarefa mais modesta e concreta, que é a de ilustrar e analisar, de forma breve, o papel e o impacto do movimento operário egípcio na revolta de 2011. Para tal, debruçar-se-á sobre o processo evolutivo do movimento operário egípcio no decurso das últimas décadas e sobre as modalidades da sua participação na revolta. $\mathrm{O}$ artigo destaca ainda as contradições percetíveis na representação que no Ocidente predomina a propósito da revolta egípcia de 2011, de maneira a melhor compreender os seus reais atores sociais (e virtuais). Longe de pretenderem resumir o que fica escrito nas secções que as precedem, as observações finais visam remeter para terrenos teóricos mais amplos, convidando assim ao aprofundamento do debate.

Da interseção de diferentes disciplinas e abordagens metodológicas resulta, aqui, o quadro teórico para proceder ao estudo do pano de fundo 
histórico, social e político em que o movimento operário egípcio se tem vindo a desenvolver nestes últimos anos. O presente artigo serve-se, ainda, de 15 entrevistas em profundidade feitas no Egito com informantes-chave no ano de 2012, bem como de informação obtida em diversas reuniões informais com membros de sindicatos independentes e ativistas políticos.

É igualmente importante salientar que, para efeitos do presente estudo, a expressão trabalho se refere a trabalho assalariado, categoria que abrange a maioria dos trabalhadores de colarinho branco e de colarinho azul, uma vez que ao longo destes últimos 30 anos de orientação económica neoliberal muitas das divisórias tradicionais (colarinho branco/classe-média versus colarinho azul/classe-operária, proletariado versus lumpen-proletariado, setores populares, etc.) foram apagadas ou, no mínimo, tornaram-se mais complexas (Hall, 1997; Marshall, 1997; Wright, 1997). No entanto, os exemplos e a análise utilizados ao longo do artigo dizem sobretudo respeito aos trabalhadores de colarinho azul egípcios. Ao longo das últimas décadas foram estes quem, efetivamente, viveu as lutas e ações mais importantes, conduzindo à revolta de 2011 e abrindo caminho para um processo revolucionário de longo prazo (Achcar, 2013).

Refira-se, finalmente, que o artigo que aqui se apresenta não se propõe analisar a relação entre os trabalhadores e o movimento islâmico (nomeadamente a Irmandade Muçulmana, a maior e mais importante organização islâmica do Egito), nem tampouco a relação entre os trabalhadores e as Forças Armadas. Cada uma destas organizações tem uma estrutura e um enquadramento histórico complexos e muito próprios, assim como caraterísticas bastante diferentes das dos movimentos religiosos e das forças armadas ocidentais. Ambas possuem vínculos históricos fortes com a população do país (e também, obviamente, com os seus trabalhadores). Assim, e por exemplo, os membros mais graduados tanto das Forças Armadas como da Irmandade Muçulmana são detentores de muitos setores industriais e financeiros, e é profunda a sua penetração na estrutura económica egípcia (se bem que os números ainda continuem em segredo). Além disso, tirando Mohamed Morsi (importante membro da Irmandade Muçulmana) e o atual presidente, Adly Mansour, desde 1952 que o Egito teve sempre dirigentes oriundos das Forças Armadas. Há, porém, que sublinhar que o movimento operário egípcio nunca dispôs, enquanto tal, de aliados políticos significativos e duradouros. Sem dúvida que a ausência de alianças políticas fortes the influenciou e limitou a capacidade organizativa, além de lhe ter travado o potencial de protagonista das transformações macropolíticas no país (El-Mahdi, 2011b: 399).

Estes temas concretos revestem-se de grande importância, merecendo ser tratados em toda a sua complexidade e multidimensionalidade. No entanto 
o presente trabalho visa apenas mostrar que o que levou ao êxito da revolta de 2011 e para além dela foram as lutas dos trabalhadores ao longo de várias décadas e o novo movimento operário atualmente em ascensão no Egito.

\section{Uma orientalização dos levantamentos árabes?}

Não obstante este artigo ter por objetivo fazer luz sobre alguns aspetos e atores específicos do processo revolucionário egípcio (a saber, o movimento dos trabalhadores e as suas lutas), aquilo a cujo desenrolar temos vindo a assistir em muitos países árabes ao longo dos últimos três anos impõe uma breve reflexão sobre o modo como diversos estudiosos e comentaristas ocidentais têm retratado a 'primavera árabe'. Uma gigantesca campanha intelectual, recheada de clichés orientalistas, tem vindo a tentar propagar o estigma de uma alegada incompatibilidade entre as populações de maioria muçulmana e a democracia. A própria metáfora das estações do ano (primavera árabe) "insere-se numa história longa de Orientalização de toda a região" (Shihade, Flesher Fominaya e Cox, 2012: 1).

Exemplo claro dessa distorção da evidência dos factos são as palavras de Thomas Friedman, jornalista galardoado com o Prémio Pulitzer, publicadas na edição de 14 de maio de 2011 do New York Times: "Nas suas raízes, esta não é uma revolta política mas sim existencial. É muito mais Albert Camus do que Che Guevara” (Friedman, 2011b).

Noutro artigo, de 1 de março de 2011, o mesmo colunista defendeu que os fatores-chave que deram aos povos do mundo árabe a inspiração para iniciar a 'primavera árabe' foram os seguintes: Obama, o Google Earth, a democracia israelita, os Jogos Olímpicos de Pequim e o Fator Fayyad (Salam Fayyad, primeiro-ministro palestiniano, mais a sua supostamente 'nova forma de governar'). A intenção de Friedman é atribuir uma responsabilidade "que, de uma forma ou de outra, remeta para o Ocidente (ou para o 'eixo euro-atlântico', conforme a preferência), de forma a não abrir mão do monopólio do conhecimento especializado" (Dixon, 2011: 309) sobre a democracia e as revoluções.

Dentro da mesma lógica situa-se Bernard Lewis, prestigiado estudioso do Islão, para quem

É claro que as massas árabes querem a mudança. E querem melhorias. Mas quando se pergunta se querem a democracia, essa é uma questão de resposta mais difícil. O que significa "democracia"? A palavra é usada com sentidos muito diversos, inclusivamente em diferentes partes do mundo ocidental. E é um conceito político que não tem história nem qualquer registo no mundo islâmico e árabe. (Horovitz, 2011) 
Deste modo, até mesmo no meio de um período intensamente revolucionário como este o 'mundo árabe' surge retratado como uma realidade estática, monolítica e a-histórica, em que as pessoas são vistas como estruturalmente atrasadas e incompetentes. Como referem Shihade, Flesher Fominaya e Cox,

na grande quantidade de relatórios, conferências, congressos e/ou documentos produzidos sobre a revolução árabe, velhas e novas narrativas de cariz orientalista continuam a apresentar o mundo árabe como sendo, ou perigoso, caótico e violento, ou estagnado, passivo, e eternamente carecido de ajuda externa (do Ocidente). (2012: 2)

A história e o quotidiano do povo árabe parecem interessar a muito poucas pessoas. $\mathrm{O}$ vigor, as esperanças, as dificuldades e a luta por uma vida melhor travada ao longo de mais de cem anos contra o colonialismo e as intromissões ocidentais, bem como contra governos injustos na própria região, permanecem soterrados debaixo de toneladas de livros e artigos em que é rendida homenagem à suposta supremacia do Ocidente. O que o novo cenário surgido com os levantamentos árabes está, hoje, a ensinar ao mundo é que

as revoltas árabes reconduziram-nos ao campo de forças da história. Estas revoltas vêm provar, até ao limite do absurdo, o falhanço de todas as teorias da modernização, ocidentalização, eurocentrismo, do Oeste como medida de todo o Resto, do fim da História, do Choque de Civilizações. (Dabashi, 2012: 15)

"O povo quer a queda do regime!" ("ash-sha'b yurid isqaat an-nizaam”), e "Liberdade, dignidade e justiça social" - duas proclamações omnipresentes nas recentes insurreições árabes e que ainda se fazem ouvir nas ruas e praças de toda a região - sugerem que as causas não se limitam à dimensão 'existencial' nem à dimensão estritamente política. Ao contrário do que afirmam muitos comentaristas ocidentais, o povo egípcio, tal como o povo tunisino, não se limitou a pedir reformas políticas ou mudança de governo; a sua reivindicação foi também por justiça social. Se atendermos à realidade dos milhões de pessoas que vivem no chamado 'mundo árabe', e cuja larga maioria é constituída por trabalhadores (palavra aqui utilizada com o sentido que lhe atribui Ricardo Antunes (2013: 8), de 'classe-que-vive-do-trabalho'), ser-nos-á bem mais fácil entender as raízes profundas dessa excecional vaga de protestos: em resumo, as condições socioeconómicas da população. Nas palavras de Gilbert Achcar, 
Para uma faísca atear um incêndio capaz de varrer de ponta a ponta toda uma região geopolítica e cultural, é forçoso que haja uma predisposição para a revolução. Dada a diversidade dos regimes políticos da região, manda a lógica que procuremos fatores socioeconómicos subjacentes, suscetíveis de terem preparado o terreno para a onda de choque sofrida pela região. Acresce que o despotismo, por si só, dificilmente será causa bastante para a eclosão e subsequente êxito de uma revolução democrática. De outro modo, não haveria como explicar o facto de esta ter triunfado no momento em que triunfou: porquê em 2011, após décadas de despotismo em terras árabes? (2013: 7)

Se no cerne das revoltas árabes estão, efetivamente, fatores socioeconómicos, daí resulta que ainda estão para vir muitas mudanças, já que, até agora, todos os governos pós-revolucionários (do Egito à Tunísia, mas não só) se revelaram incapazes de dar resposta às reivindicações de justiça social que deram origem às insurreições em toda a zona árabe.

\section{A virtualização da revolta egípcia? Análise breve dos fatores sociais e virtuais da insurreição}

A 'revolução egípcia' terá sido uma 'revolução-Facebook' ou uma 'revolução-Twitter', como tantas vezes se diz, ou foi antes uma luta coletiva que esteve a fervilhar durante estes últimos anos? Seria útil dar resposta a esta pergunta, para evitar que a análise do papel dos trabalhadores egípcios na revolta de 2011 se deixe emaranhar em perspetivas vagas e difusas. Se nos ativermos à evidência factual, não parece haver uma base científica firme para colocar a tónica no papel das redes sociais. Veja-se o que escreve, a propósito, Ursula Lindsey:

Já em 25 de janeiro havia falta de rede na praça Tahrir, para uso dos telemóveis por parte dos manifestantes que ali haviam acorrido. No dia seguinte as operadoras de telecomunicações receberam das autoridades instruções no sentido de baixar os limites da taxa de transmissão de dados - o que é uma forma de reduzir a velocidade da Internet. Na noite de 27 de janeiro a Internet deixou de funcionar. O serviço de envio de mensagens foi desativado. Na manhã seguinte toda a rede de cobertura de telemóveis do Egito se encontrava em baixo. Responsáveis da Vodafone, uma das principais operadoras de telecomunicações do país, disseram que, em obediência à lei egípcia, que confere às autoridades amplos poderes em caso de emergência, foram obrigados a respeitar as ordens do governo para desligar a rede. (2012: 53)

Daí que, à medida que o dia 28 de janeiro, 'dia da ira', se aproximava, a única maneira de comunicar no país fosse através da organização de reuniões presenciais: não havia Facebook, nem Twitter, nem Youtube, nem 
tampouco telemóveis. Isso quer dizer que o papel das redes sociais na ajuda dada aos ativistas com vista a mobilizar as pessoas e a organizar a insurreição nas ruas foi verdadeiramente insignificante. Entre os que perfilham esta opinião conta-se Richard Haass, presidente do Conselho para as Relações Externas e antigo diretor para o planeamento político do Departamento de Estado dos EUA, que sublinha:

As redes sociais são um fator significativo, mas tem-se exagerado quanto ao papel que desempenham. Estão longe de ter sido a primeira tecnologia desestabilizadora a entrar em cena: cada um em sua época, a imprensa, o telégrafo, o telefone, a rádio, a televisão e a cassete colocaram desafios à ordem vigente. E tal como essas tecnologias que as antecederam, também as redes sociais não são determinantes: podem ser reprimidas pelos governos, da mesma forma que podem ser por estes empregadas para motivar os seus apoiantes. (2011: 115)

Esta é também a opinião de Beinin e Varel, segundo os quais, tanto no caso egípcio como no tunisino,

A análise imediatista de uma boa parte dos meios de comunicação de massa centrou a atenção nas redes sociais da Web 2.0 - blogues, Facebook, Twitter, Flickr, etc. -, vistos como mecanismos viabilizadores da mobilização dos movimentos insurretos. [...] Houve quem referisse o fluxo informativo relativamente livre existente um pouco por todo o mundo árabe em consequência dos canais de televisão por satélite, especialmente a Al-Jazeera e a al-Arabiyya. Sem dúvida que estes aspetos ajudam à explicação. Mas a Al-Jazeera começou a transmitir em 1996. Teve, na prática, um papel condutor na revolta tunisina. Mas reagiu com lentidão na cobertura dos acontecimentos de 25 de janeiro no Egito, circunstância que, na opinião de muitos, se terá devido à pressão exercida pelo Emir do Qatar, patrono do canal. Posteriormente, e não obstante os seus repórteres terem sido presos e as câmaras confiscadas em 30 de janeiro, a Al-Jazeera compensou largamente o tempo perdido. Quanto aos telefones móveis, muito mais utilizados na mobilização política do que o Facebook e o Twitter, desde 1998 que se encontram disponíveis no Egito. (2011b: 248)

Isto só prova que as redes sociais não bastam para fazer a revolução, e também, como é óbvio, que as revoluções não se fazem a pedido. Não se deve, contudo, subestimar o papel das redes sociais no Egito. Leia-se o que, em 18 de julho de 2012, se noticiava no Abram Online:

O Egito conta com um total de 11,3 milhões de utilizadores do Facebook, sendo 1,6 milhões o número de novas contas criadas entre janeiro e junho de 2012, 
segundo dados estatísticos do Relatório sobre as Redes Sociais Árabes (Arab Social Media - ASMR). Isso faz com que o Egito, que é, em população, o maior país do mundo árabe, seja também o maior utilizador desta popular rede social na região. De acordo com o referido relatório, em finais de junho de 2012 o mundo árabe tinha um total de 45,2 milhões de utilizadores do Facebook, uma subida em relação aos 37,4 milhões que tinha em janeiro. Em junho de 2011 o número cifrava-se em 29,8 milhões, o que aponta para um aumento anual de 50\%. O relatório mostra ainda que o número de utilizadores do Facebook no mundo árabe praticamente triplicou nos últimos dois anos, passando de 16 milhões em meados de 2010 para 45 milhões neste último verão. A juventude árabe - jovens com idades entre os 15 e os 29 anos constitui cerca de $70 \%$ do total de utilizadores do Facebook, e essa percentagem tem-se mantido relativamente estável. (2012a)

Não são novidade, na produção bibliográfica, as discussões sociológicas sobre o potencial dos novos meios de comunicação para moldar a sociedade. Elas tiveram início com o livro de Manuel Castells The Rise of the Network Society (1996), a que se seguiu, mais recentemente, Communication Power (2009). Alguns estudiosos reconhecem o potencial das redes sociais enquanto veículo de difusão da democracia (Poster, 1995), mas outros há que apontam severas limitações no que toca ao papel dos novos meios de comunicação na política e na democracia (Howard, 2011). Assim, é frequente as discussões a propósito deste tema dividirem-se entre

Aqueles que acentuam a função controladora dos novos meios de comunicação, vistos, assim, como um novo instrumento repressivo no arsenal dos ditadores, e aqueles que os encaram como uma ferramenta de abertura democrática. Alguns autores fazem notar que, mesmo nas sociedades democráticas, a nova tecnologia representa uma ameaça grave para a liberdade e privacidade dos cidadãos. Outros, pelo contrário, deixam-se muitas vezes entusiasmar com o potencial que os novos meios possuem para moldar a política e abrir espaço a uma nova esfera pública, especialmente nas sociedades caraterizadas pela ausência de uma esfera pública autêntica. Há, no entanto, autores a quem se devem propostas mais equilibradas quanto àquilo que são as armadilhas e o potencial dos novos média, a sua função de controlo e a sua função emancipatória. (Khondker, 2011: 676)

Além disso, uma análise global não deverá subestimar o papel dos meios de comunicação social convencionais e a relação de reciprocidade que mantêm com os novos meios. Na sua análise do papel da Al-Jazeera (em árabe) e de muitos outros canais no que concerne à apresentação das notícias sobre as revoltas árabes, Manuel Castells sublinha os seguintes aspetos: 
A Al-Jazeera coligiu a informação divulgada pelas pessoas na internet, servindo-se destas como fonte, e organizou grupos no Facebook, retransmitindo de seguida esses dados através da rede de telemóveis sob a forma de notícias gratuitas. Assim nasceu um novo sistema de comunicação de massa, uma mistura de televisão interativa, Internet, rádio e sistemas de comunicações móveis. A comunicação do futuro já está a ser utilizada pelas revoluções do presente. [...] É claro que não foram as tecnologias da comunicação que geraram a insurreição, a qual teve origem, isso sim, na pobreza e na exclusão social de que padece uma grande parte da população nesta falsa democracia. (2011)

Como se pode ver, e é defendido por muitos autores, não há que questionar o papel dos meios de comunicação social tradicionais e dos mais recentes na sociedade egípcia, e nomeadamente na agitação vivida em 2011. O que aqui está em causa, porém, é entender o seu papel concreto. Alguns estudiosos acreditam que aquilo que se passou teve mais a ver com a criação de novos espaços num tipo de comunicação alternativa, rápida e não controlada, do que com a organização da revolução e de confrontos de rua ou com a formação de uma consciência política. Um desses estudiosos é Abdulla Rasha, que salienta nitidamente estes aspetos quando escreve:

A Internet foi a ferramenta que veio mostrar a todas as vozes dissidentes do Egito que não só não estão sozinhas, como de facto têm a acompanhá-las pelo menos centenas de milhares de pessoas que buscam a mudança. Não foi o Facebook que acorreu à Praça Tahrir, foi o povo. Não foi o Twitter que acorreu à praça Al-Ibrahim Qaied, foi o povo. Mais de um terço da população do Egito, com os seus oitenta milhões de habitantes, continua analfabeta, e só $25 \%$ dos egípcios usam a Internet. (2011: 41)

Não se deve esquecer, além disso, que a maior parte daqueles que participaram na revolta de 2011 pertenciam às classes subalternas (El-Mahdi, 2011a), o que quer dizer que eram pessoas com um acesso limitado à Internet e às redes sociais.

Tendo em conta tudo isto, é de concluir que não se deve procurar as subjetividades revolucionárias nos likes do Facebook nem nos tweets, mas sim na grande quantidade de lutas populares e protestos de rua travados desde há décadas, e mais especificamente no crescente movimento operário, que desde há muito vem sendo chamado "o maior movimento social registado em mais de meio século” (Beinin, 2009: 77). 


\section{Os anos quentes no contexto industrial do Egito pós-revolta: das reivindi- cações económicas às reivindicações políticas}

Segundo o Centro Egípcio para os Direitos Sociais e Económicos (Egyptian Centre for Social and Economic Rights - ECESR),

Em 2013 os trabalhadores egípcios levaram a cabo 2486 ações de protesto, 2243 das quais durante o reinado do agora deposto presidente Mohamed Morsi. Durante o governo interino de iniciativa militar realizaram-se, no total, 243 ações de protesto.

Nesse ano os trabalhadores organizaram protestos à média de 6,1 por dia. O número ficou abaixo do total atingido em 2012, ano em que as manifestações chegaram às 3300. O número global de protestos ocorridos em 2013 superou o de 2011, ano em que se registaram 1300 ações. (Ashraf 2013 - Daily News Egypt, 31, dezembro de 2013)

Nos últimos três anos a agitação laboral estendeu-se não apenas ao Cairo, a capital, mas também a muitas outras cidades do país, como Alexandria, Tanta, Suez, Porto Said, etc. No entanto, como sempre ao longo das últimas décadas, as mais importantes ações no setor da indústria ocorreram na empresa estatal de Fiação e Tecelagem Misr, em Mahalla (conhecida como al-Ghazl Mahalla), o maior complexo industrial do país na área têxtil. Por toda a parte os operários avançaram com as mesmas reivindicações: salário mínimo, contratação definitiva, seguro de saúde e saneamento dos gestores corruptos das fábricas do Estado.

Ao longo dos últimos três anos o Estado pós-revolucionário respondeu a estas ações coletivas com a repressão, tendo sido frequentes as investidas brutais da polícia contra os operários em greve. Esbirros reentraram em cena um pouco por todo o país (em 22 de julho de 2012, operários da fábrica têxtil Al-Samouli, de Mahalla, foram baleados quando em ação de protesto, numa emboscada armada por 'assaltantes desconhecidos'). Alguns operários foram, inclusivamente, mortos e vários ficaram feridos em resultado desses ataques organizados. Algumas dessas greves foram, todavia, (parcialmente) bem-sucedidas. Em diversos casos os trabalhadores conseguiram concessões da parte dos diferentes governos que vieram depois da revolta de 2011. Exemplo claro de um desfecho positivo para as lutas dos operários neste período pós-revolta é o da empresa Mahalla: em 2012, após uma greve que durou sete dias, os operários conquistaram um prémio de participação nos lucros referente a seis meses e meio, além de um aumento do benefício a receber no momento da reforma. Este acordo abrangeu a totalidade das fábricas têxteis do setor público, que hoje no Egito se calcula que empreguem cerca de 100000 operários (Alexander, 2012a). 
Mas o que verdadeiramente merece destaque, no que diz respeito às ações ocorridas no setor industrial do período pós-revolta, é a crescente natureza política das reivindicações dos trabalhadores. A este propósito, é importante a informação constante da declaração produzida em 2012 pelos operários de Mahalla, intitulada 'Mensagem ao Presidente' (i.e., ao presidente Mohamed Morsi, membro da Irmandade Muçulmana):

Durante muitas décadas os operários foram vítimas de marginalização, pobreza e humilhações. Por isso eles devem ser, neste momento, a grande preocupação do presidente, porque nada lhes interessa mais do que cumprir os objetivos da revolução: a liberdade e a justiça social. Queremos lembrar ao presidente que foram os operários quem derrubou o regime opressor. (Atef, 2012)

A interpenetração entre, por um lado, a luta pela justiça social (materializada na exigência de melhores salários, melhores condições de trabalho e segurança no emprego) e, por outro lado, a batalha pela tabrir ('liberdade') e pela tathir - quer dizer, o 'saneamento' dos gestores corruptos das fábricas e instituições do setor público - não constitui novidade no Egito, antes caraterizou, invariavelmente, as iniciativas operárias durante as décadas precedentes (Alexander, 2012b). É importante, a este propósito, recordar que desde 1952 que as greves, os ajuntamentos públicos não autorizados e os protestos de rua estiveram proibidos por lei. Por este motivo, as ações e manifestações dos operários representaram sempre um gesto coletivo corajoso, com um forte cunho antirregime (que o mesmo é dizer, político).

No entanto, as expressas reivindicações políticas dos operários de Mahalla (ou seja, a 'Mensagem ao Presidente') e a imensa vaga de greves ocorrida em todo o país na fase pós-revolta vieram alterar profundamente o rumo do debate político, uma vez que até àquele momento a atenção estivera exclusivamente voltada para questões como a nova constituição, as eleições, as leis islâmicas e o parlamento. As greves e a referida 'mensagem' contribuíram para que as atenções se transferissem do estrito foro político-institucional para os problemas de natureza socioeconómica respeitantes à ampla base social formada pelos pobres e marginalizados.

Outro exemplo claro da interpenetração crescente das reivindicações de natureza económica e política presentes nas lutas dos trabalhadores egípcios foi o comprometedor relatório elaborado em 2012 pelo Centro Sindical e Operário (Centre for Trade Unions and Workers - CTUW), a Conferência Trabalhista Democrática do Egito (Egyptian Democratic Labour Congress - EDLC), e o Centro de Serviços Sindicais e do Operariado (Centre for Trade Unions and Workers' Services - CTUWS): 
A resposta dada pelo governo às greves dos operários não é a resposta própria de um governo saído de uma revolução. Pelo contrário, ele recorreu às mesmas táticas usadas pelo antigo regime. (Abram Online, 2012b)

No relatório, o presidente Morsi e a Irmandade Muçulmana (de que Morsi já era membro de longa data) eram também acusados de introduzir "alterações perturbadoras na Lei Sindical n. ${ }^{\circ} 35$, de 1976, que regula a atividade sindical”, e de não conferirem aos operários a liberdade e independência que estes merecem, "não obstante existirem hoje em dia no país 1200 sindicatos independentes" (Ahram Online, 2012b).

Muitos destes sindicatos independentes integram atualmente as duas novas federações sindicais, designadamente a Federação Egípcia dos Sindicatos Independentes (Egyptian Federation of Independent Trade Unions - EFITU) e a Conferência Trabalhista Democrática do Egito (Egyptian Democratic Labour Congress - EDLC).

Apesar de os trabalhadores egípcios não parecerem aceitar a desmobilização política - e por isso fizeram frente, primeiro ao presidente Morsi e à Irmandade Muçulmana, e depois ao governo de iniciativa militar -, as novas federações são bastante "débeis no que toca a recursos e a capacidade organizativa” (Beinin, 2013). Como assinalam Andrea Teti e Gennaro Gervasio, até agora não tem havido coordenação e unidade nas suas ações:

No que diz respeito ao movimento sindical independente, coloca-se o problema de chegar a um certo nível de coordenação com vista à ação unitária. A EFITU, que é a nova federação independente, cresceu a um ritmo muito rápido desde que foi criada em 31 de janeiro de 2011, compreendendo hoje mais de duzentos sindicatos de dimensão variada. Conseguir assegurar a "democracia interna" é algo que lhe vai ser fundamental se quiser manter o nível de legitimidade e mobilização alcançado pelos trabalhadores na fase que antecedeu a Revolta de Janeiro e de então para cá. Também já se fizeram sentir os primeiros sinais de brechas dentro da EFITU: no passado outono as duas principais organizações que lhe deram origem - a RETA, de Kamal Abu Eita, e o CTUWS, de Kamal Abbas - desentenderam-se, tendo este último abandonado a Federação. As divergências tiveram a ver, no plano imediato, com o "financiamento estrangeiro", mas também com os grandes objetivos estratégicos do movimento sindical, mostrando-se a RETA favorável a campanhas de sindicalização dirigidas ao ainda considerável setor público, ao passo que o CTUWS pretende alargar o esforço de sindicalização ao setor privado e particularmente às Zonas Económicas Especiais, onde são ainda mais restritos os direitos dos trabalhadores. (2012: 109) 
Como refere Beinin, isto provavelmente só acontece "porque entre o início da década de 1950 e 2011 o Egito não conheceu minimamente o sindicalismo democrático" (2013). Deve, porém, reconhecer-se que hoje em dia as reivindicações dos trabalhadores egípcios comportam de forma clara (com diferentes níveis de intensidade, consoante o momento) uma vertente política e uma vertente económica.

\section{Trabalhadores egípcios, um ator social desconhecido?}

De acordo com dados oficiais fornecidos pela Agência Central para a Mobilização Pública e a Estatística (Central Agency for Public Mobilisation and Statistics - CAPMAS), o setor manufatureiro é o segundo maior da economia egípcia, depois da agricultura. Numa população de 82,3 milhões, a força de trabalho é composta por mais de 26,1 milhões de habitantes. Até ao final de 2010 o número de empregados era de cerca de 23,8 milhões (sendo 19,1 milhões homens e 4,6 milhões mulheres). As estatísticas oficiais referem cerca de 2,3 milhões de desempregados, o que, em 2011, correspondia a uma taxa de desemprego de $9 \%$ aproximadamente (CAPMAS, 2011). Segundo o Relatório do Centro para a Solidariedade egípcio, no entanto, quase "60\% dos trabalhadores estão empregados na economia informal" (Egyptian Solidarity Centre, 2010: 5). A julgar pelo abrandamento do crescimento económico associado à crise económica global que rebentou em 2008, e que teve um forte impacto sobre a estrutura económica do Egito, muitos outros observadores creem igualmente que, nos últimos cinco anos, a taxa de desemprego real é muito superior àquilo que mostram os números oficiais. Daí que haja muitas opiniões que consideram que a crescente taxa de desemprego constitui uma das causas principais das recentes vagas de greves e protestos no país.

No entanto, não se pode considerar que as últimas vagas de greve no Egito sejam um acontecimento excecional. Com efeito, pode dizer-se que há no Egito uma 'velha tradição' de lutas e greves por salários mais altos e melhores condições de trabalho. Como é largamente consabido, a primeira greve de que existe registo no mundo ocorreu no Egito há milhares de anos: tratou-se de uma "ocupação que durou três dias, levada a cabo pelos trabalhadores das pirâmides por causa de queixas relacionadas com a paga do trabalho" (Trumka, 2010:3). O movimento operário egípcio da era moderna começou no Cairo com uma greve de trabalhadores gregos, os enroladores de cigarros, em 1899. Data de então a criação do primeiro sindicato no país. Algumas décadas volvidas, foram criados no Cairo e em Alexandria diversos sindicatos, a maioria dos quais para enquadramento dos trabalhadores dos comboios e elétricos. Desde as suas origens, 
estas organizações tiveram uma feição política e fortemente anticolonial (Egyptian Solidarity Centre, 2010: 8). Em março de 1938 os representantes de 32 sindicatos, a maioria deles com sede no Cairo, criaram a primeira federação sindical independente, a Federação Geral de Sindicatos Operários do Reino do Egito (GFLUKE).

Durante a Segunda Guerra Mundial os sindicatos egípcios foram, finalmente, legalizados, mas simultaneamente o Estado alargou o controlo que tinha sobre eles. Assim, só eram permitidos sindicatos segmentados, ou seja, ligados a um local de trabalho específico. No entanto o movimento sindical alastrou a todo o país de forma impressionante: "em maio de 1944 estavam inscritos oficialmente 350 sindicatos, com um total de cerca de 120000 membros" (Egyptian Solidarity Centre, 2010: 13). Durante os anos da guerra a classe trabalhadora do setor da indústria cresceu substancialmente (até cerca de 623000 operários fabris), e de forma crescente se fez também sentir, entre outubro de 1945 e janeiro de 1952, o caráter anticolonial do movimento operário egípcio.

Quando, em 23 de julho de 1952, Gamal Abdel Nasser e os Oficiais Livres derrubaram a monarquia, criando um Conselho de Comando da Revolução (RCC), muitos trabalhadores apoiaram com entusiasmo o regime militar. Os Oficiais Livres prometeram independência nacional e justiça social plenas. De facto, com Nasser a presidente uma vaga de reformas empreendidas de cima para baixo começou a transformar o país, em sintonia com o movimento anticolonial popular e com o nacionalismo 'anti-imperialista'. Entre as reformas empreendidas destacam-se a da legislação laboral, a da reforma agrária (deixada, em grande parte, por concluir), a eletrificação do país, o acesso generalizado à educação, e a criação de um sistema de saúde moderno. Em 1954 foram nacionalizados todos os bancos, assim como todas as empresas com mais de 200 empregados e os latifúndios. Os trabalhadores das empresas nacionalizadas passaram a ser funcionários do Estado, e com isso melhorou o seu nível de vida. Entre 1960 e 1964 os salários reais aumentaram um terço, enquanto o número de horas de trabalho semanais diminuía $10 \%$. O governo assegurava a todos os licenciados um emprego de colarinho branco, e um emprego de colarinho azul a quem terminasse o ensino secundário (Egyptian Solidarity Centre, 2010: 17). O preço dessas reformas foi a suspensão da participação dos trabalhadores na vida política e a dura repressão das suas lutas ou greves independentes: "não houve no Egito greves legais desde que, em março de 1954, Nasser consolidou o poder" (Beinin, 2009: 69). Com Nasser o Egito criou um sistema coerente, o qual, contudo, deve ser sujeito à crítica, uma vez que reprimiu, entre muitas outras coisas, a autonomia do movimento operário: 
Nasser apostou na industrialização para escapar à especialização internacional e colonial, que confinava o país ao papel de exportador de algodão. O sistema que criou manteve uma divisão de rendimentos que favorecia as classes médias em expansão, sem empobrecer as massas populares. (Amin, 2011: 11)

Não obstante a política económica de Nasser, o índice dos salários reais caiu várias vezes entre 1964 e 1976, o que teve como resultado o deflagrar de ações coletivas de trabalhadores por todo o país (Beinin, 1993). A ação mais importante teve lugar na Fiação e Tecelagem Misr, em Mahalla al-Kubra: "Uma greve com ocupação de instalações, durante três dias do mês de março de 1975, levou a um aumento salarial de 9 para 15 EGP diários para todos os operários da área da produção no setor público egípcio" (ibidem: 70).

Em 1970, com a chegada ao poder de Saddat - que lançou o programa 'infitah' ('porta aberta'), destinado a reintroduzir o setor privado e atrair capital estrangeiro, reduzindo, ao mesmo tempo, o papel do Estado na área económica e industrial -, deu-se no país uma mudança radical, tanto a nível político como a nível económico. A abertura da economia egípcia trouxe rápidas transformações, 'gerando um surto imobiliário e criando uma nova burguesia parasitária’ (Hinnebusch, 1985: 69-70). As condições de vida das massas populares pioraram em poucos anos, e em 1977 rebentaram por toda a parte as 'revoltas do pão'. Os trabalhadores consideraram as novas reformas governamentais um ataque direto ao seu nível de vida. Mais de 100 pessoas foram mortas nestas revoltas, em que os trabalhadores da indústria tiveram um papel significativo. As suas ações constituíram "uma resposta imediata às reformas inspiradas pelo FMI, mas foram, também, resposta a queixas mais antigas" (Beinin, 2009: 70). Os tumultos foram espontâneos e tiveram um caráter nacional, contudo faltou unidade e organização ao movimento. No entanto, ele acabou por ser importante para as classes populares do país, na medida em que obrigou o governo a recuar parcialmente nos seus planos neoliberais (Posusney, 1993: 222).

Após a morte de Sadat (1981), Hosni Mubarak assumiu a continuidade do processo. Desde o início que prosseguiu e aperfeiçoou a mesma estratégia de 'abertura', a que chamou 'infitah produtiva'. Sob a sua orientação assistiu-se, também, ao reforço da economia de mercado livre e voltada para a exportação. Em conformidade com o Programa de Ajustamento Estrutural assinado em 1991 com o Fundo Monetário Internacional, o governo egípcio privatizou segmentos do setor público e liberalizou os preços e as rendas.

Mubarak adotou uma liberalização mais agressiva da economia. Em 1991 o Egito deu início a um programa de ajustamento estrutural maciço. O esquecimento a que 
o governo votou o setor agrícola durante as décadas de 1980 e 1990 conduziu ao empobrecimento e à marginalização dos pequenos camponeses. Ao mesmo tempo, as políticas neoliberais geravam tensões no interior da classe dominante. (Munif, 2013: 206)

$\mathrm{O}$ aprofundamento das políticas neoliberais nos anos 80 e 90 apagou em definitivo o que restava do Estado Nasser. O único aspeto que sobreviveu foi o aparelho de coerção autoritário. Este de pouco serviu, no entanto, para impedir os trabalhadores egípcios de voltarem de novo às ruas: de 1984 a 1989 e em meados da década de 1990 verificaram-se entre 25 e 80 ações coletivas por ano (El Shafei, 1995).

Depois de 2004 teve início uma imensa vaga de privatizações de empresas públicas. Foi a maior venda de sempre do setor público egípcio, em resultado da qual o Banco Mundial classificou o Egito como sendo, no plano económico, um dos dez países mais 'reformadores' do mundo (World Bank, 2007: 1). Enquanto isso, no entanto, o Egito tornou-se um dos países em que os preços dos alimentos subiam a pique, ao passo que os salários permaneciam estagnados. Tal situação levou mais uma vez os trabalhadores para as ruas: de 1998 a 2009 "mais de dois milhões de operários participaram em mais de 3300 ocupações de fábricas, greves, manifestações ou ações coletivas afins" (Beinin, 2011: 181).

\section{Número de ações}

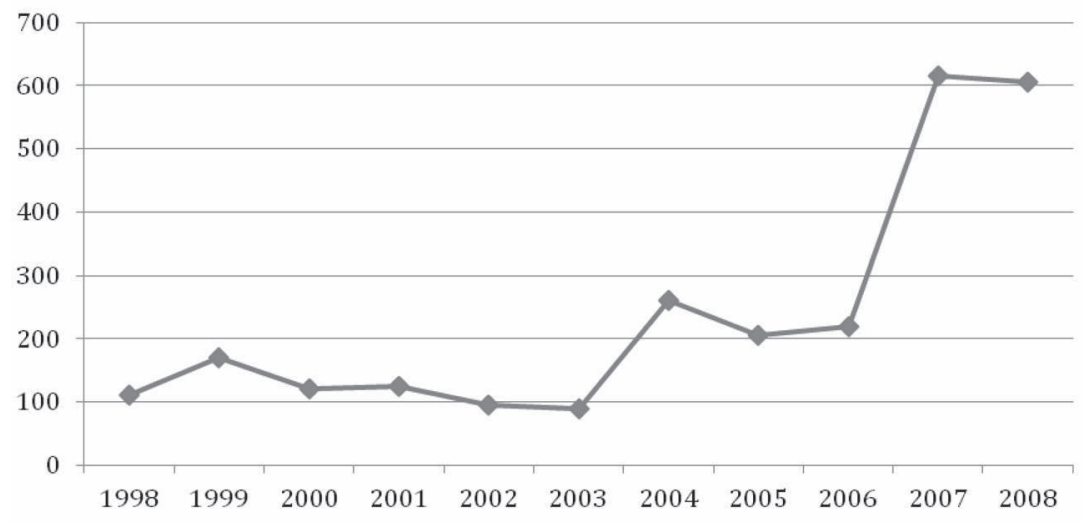

FIGURA 1 - Ação reivindicativa dos trabalhadores egípcios entre 1998 e 2008

Fonte: Gráfico elaborado com base no Centro da Terra para os Direitos Humanos (Land Centre for Human Rights - LCHR), disponível em http://www.lchr-eg.org 
Como se pode ver pela Figura 1, o ponto de viragem na ação coletiva dos trabalhadores deu-se em dezembro de 2006, quando os operários de Mahalla fizeram uma greve de vários dias:

Após uma semana marcada por reivindicações e pela organização de pequenas ações de protesto, 24000 trabalhadores entraram em greve no dia 7 de dezembro de 2006, quando milhares de operárias da fábrica abandonaram os seus postos de trabalho e se dirigiram até ao setor onde trabalhavam os homens, entoando: "Onde é que estão os homens? As mulheres estão aqui!”. Juntando fileiras, mulheres e homens marcharam em direção ao centro da fábrica, situado na Praça Tala't Harb. Nos três dias que se seguiram, mais de 10000 operários em greve ocuparam a fábrica vinte e quatro horas por dia, formando um comité de greve para organizar os aspetos logísticos, falar à comunicação social e negociar com os representantes da entidade empregadora no local. (El-Mahdi, 2011b: 388)

A ação foi vitoriosa, mas mais significativo foi o facto de ela ter assinalado, no Egito, um salto qualitativo em relação a anteriores iniciativas no âmbito laboral. E isso não só porque serviu de inspiração a outros trabalhadores da indústria (dos setores público e privado) e aos trabalhadores de colarinho branco (cobradores de impostos, funcionários dos correios, administradores escolares, trabalhadores dos transportes, funcionários dos centros de informação do Estado, médicos e farmacêuticos), que desencadearam importantes ações de afirmação laboral em todo o país, mas também, e principalmente, porque representou uma viragem relevante na forma de organizar as greves. Foram criadas novas comissões de greve, totalmente autónomas em relação aos tradicionais sindicatos estatais, o que por sua vez veio proporcionar a formação e experiência necessárias ao aparecimento de sindicatos independentes.

O dia 6 de abril de 2008, dia da fundação do 'Movimento da Juventude 6 de Abril', é outra data importante para o movimento operário egípcio. Houve um esforço imenso para organizar uma greve geral em todo o país, de apoio à greve empreendida pelos operários de Mahalla contra a alta dos preços dos alimentos. Foi a primeira tentativa do género na história do movimento operário do Egito. A greve geral não chegou a realizar-se, mas houve ações de massa por parte, quer dos operários, quer dos habitantes de Mahalla. O governo precisou de dois dias para pôr fim às manifestações de rua, também chamadas 'Intifada de Mahalla'. Foram mortas três pessoas e centenas de trabalhadores sofreram a prisão e a tortura. No entanto, as greves, as ocupações e os protestos continuaram durante meses noutros locais, levando à formação, em 2009, dos primeiros sindicatos independentes dos cobradores de impostos do país. 


\section{Papel, organização e participação dos trabalhadores na revolta de 2011}

Para muitos estudiosos e ativistas, os primeiros sinais da crescente oposição política vivida no Egito foram dados pelos protestos de setembro de 2000, quando dezenas de milhares de egípcios saíram à rua em solidariedade com a intifada palestiniana. Mas a fúria contra o regime só pôde explodir abertamente em todo o país com o deflagrar da guerra do Iraque, em 21 de março de 2003. Nessa altura,

os egípcios ocuparam a Praça Tahrir num protesto que começou por ser sobre a invasão do Iraque pelos EUA e logo se transformou numa ação contra o presidente Hosni Mubarak e o seu regime. (Schemm, 2012: 85)

Numa tentativa de unificar os partidos políticos e os movimentos sociais (ONGs, associações, etc.) que exigiam a alternância do poder, foi lançado em 2004 o 'movimento Kefaya'. Inicialmente o Kefaya (palavra árabe para basta) conseguiu mobilizar amplos setores da sociedade egípcia que criticavam Mubarak e se opunham à sua sucessão hereditária pelo filho, contudo o movimento acabaria por se revelar incapaz de ultrapassar muitos dos obstáculos aos esforços realizados no sentido das reformas e da participação política (Al-Sayyid, 2009; Al-Din Arafat, 2009). Apesar deste fracasso, o movimento Kefaya serviu de inspiração a importantes (ainda que só parciais) reformas no plano social e jurídico. Além disso, ajudou a criar uma comunidade online, congregando, pela primeira vez, meios de comunicação social e movimentos oposicionistas (Levinson, 2005).

Em abril de 2008, como já foi referido na secção anterior, nasceu outro movimento importante: o 'Movimento da Juventude 6 de abril', formado - de maneira (mais ou menos) espontânea - a partir dos esforços para organizar a greve geral nacional contra a alta dos preços dos alimentos, em apoio à greve dos operários da cidade de Mahalla:

Desde a Segunda Intifada, ocorrida no ano 2000, diversos grupos constituíram coligações para apoiar a luta dos palestinianos e opor-se à guerra no Iraque. Dessas lutas emergiram dois grupos importantes: (1) o Kifaya, uma coligação de grupos liberais, de esquerda, e islâmicos que organizavam protestos e ações simbólicas para fazer frente ao poder autoritário de Mubarak; e (2) o Movimento da Juventude 6 de Abril, formado sobretudo por jovens da classe média que começaram a apoiar as lutas dos trabalhadores em abril de 2008. Estes movimentos sociais contribuíram para fazer frente à hegemonia política da elite. (Munif, 2013: 208) 
Neste crescente movimento oposicionista de cerca de uma década, o papel dos trabalhadores foi significativo tanto quantitativa como qualitativamente. Estima-se que, entre os anos de 2006 e 2009, mais de 1,7 milhões de trabalhadores tenham participado em ações diversas (El-Mahdi, 2011b: 388), ao mesmo tempo que eram introduzidas novas variantes organizativas em resultado do desenvolvimento de processos de democratização interna e da adoção de novas táticas de confronto. Em muitos casos, operários e trabalhadores em geral criaram os seus próprios comités de greve, nomearam e elegeram novos dirigentes à margem dos sindicatos oficiais do Estado, organizaram e encetaram negociações independentes com as autoridades, criaram um novo arsenal de instrumentos de luta, desde motins de rua a várias outras formas de protesto, e por último, mas não menos importante, aprenderam a gerir a forma de comunicar com os média.

Aquilo que levou os trabalhadores a criar novos comités locais e a eleger novos dirigentes foi a necessidade não só de fugir ao controlo dos sindicatos estatais (na sua maioria considerados corruptos ou cúmplices dos gestores públicos e privados), mas também de convocar uma série de greves de muitos dias, de maneira a resistir à repressão estatal e ao contra-ataque do patronato. Este tipo de greve exige um nível de organização mais elevado, uma vez que obriga os trabalhadores a criar mecanismos para pernoitar e providenciar refeições diárias nos locais de trabalho, bem como para os proteger, e exige também uma direção capaz de manter os trabalhadores motivados e unidos durante períodos mais longos.

Embora as reivindicações dos trabalhadores fossem essencialmente de natureza económica, não foi incomum a apresentação de reivindicações de caráter político, e menos incomum ainda as denúncias contra o regime de Mubarak e a repressão do Estado. Há ainda outros aspetos importantes a sublinhar: o movimento operário egípcio era - e continua a ser - demasiado fragmentado e desorganizado. A verdade é que ele se revelou incapaz de moldar ou encabeçar o movimento de oposição política no período anterior a 2011, tendo a sua intervenção em toda a agitação vivida nesse ano sido importante do ponto de vista quantitativo, ou seja, em função do grande número de trabalhadores presentes nos protestos de rua. Atente-se no que, a este propósito, afirma Joel Beinin:

O movimento operário independente não estava preparado para assumir um papel de direção quando, em janeiro de 2011, a agitação alastrou pelo mundo árabe. Não possuía uma direção reconhecida a nível nacional, dispunha de escassos recursos organizativos e financeiros, contava com um apoio internacional limitado, não tinha um programa político, e o programa económico que tinha era mínimo. (2012: 1) 
No entanto, e como já ficou dito atrás, os operários constituíram uma parte significativa dos 18 dias da revolta egípcia. Isso mesmo resulta das afirmações contidas na entrevista pela autora a Fatma Ramadan, dirigente da Federação Egípcia de Sindicatos Independentes:

Havia operários de quase todas as siderurgias na Praça Tahrir ou nos protestos de Gizé, tal como estavam presentes trabalhadores das empresas de açúcar em al-Fayyum ou nas ruas de Ismailia e de Kafr Sheikh. Como é possível pensar que não havia operários a participar nos protestos numa cidade de operariado como é Mahalla al-Kubra, por exemplo, onde mais de 500000 pessoas desceram à rua todos os dias durante a revolução? Se aqueles dois milhões de pessoas a protestar e a lutar todos os dias em Alexandria não eram operários, então eram quem?

Outros trabalhadores entrevistados no verão de 2012 descreveram uma situação idêntica. Um deles, AA, um dirigente sindical local que trabalha para a Autoridade do Canal do Suez, afirmou:

Durante esse gloriosos 18 dias da revolução estávamos todos nas ruas. Nenhum de nós ficou em casa ou foi trabalhar. Estávamos todos juntos, ainda que, ao princípio, não estivéssemos muito bem organizados. E não descemos à rua como membros do sindicato, mas como pessoas. [...] Claro que andámos com bandeiras, mas eram bandeiras do Egito, não eram bandeiras do sindicato.

RK, jovem operária de uma fábrica têxtil de Alexandria, expressou esta ideia ainda com mais clareza:

Eu e os meus amigos andámos quase todos os dias nos protestos de rua. Bem, diga-se que, no início, nem todos lá andaram, mas quando ficou claro que as manifestações se estavam a aguentar e que qualquer coisa de inesperado estava a acontecer nesses dias por todo o Egito, nessa altura eu vi os meus amigos e colegas todos nas ruas.

Estima-se que entre os dias 25 de janeiro, data do início das manifestações, e 11 de fevereiro, que foi quando Hosni Mubarak se demitiu oficialmente, pelo menos 15 milhões de pessoas, de uma população de cerca de 83 milhões - ou seja, mais de $20 \%$ da população - participaram nas manifestações de massas (Amin, 2011: 13).

Todos os ativistas e sindicalistas entrevistados confirmam a ideia de que a revolta egípcia teve, inequivocamente, um cunho nacional e popular. A Praça Tahrir, na cidade do Cairo, tornou-se o símbolo da revolução, sobre ela recaindo o foco principal da cobertura mediática ocidental, 
sem no entanto ter sido o local privilegiado, visto que todo o país esteve envolvido, desde as cidades e províncias até aos lugares mais remotos. Segundo os entrevistados, os manifestantes de outras cidades, como Suez, Porto Said e Alexandria, deram mostras de uma ousadia ainda maior. Em Alexandria, por exemplo, e ao invés do que, de um modo geral, aconteceu no Cairo, os manifestantes não se limitaram a ocupar uma praça; foram aparecendo todos os dias, de cada bairro e de cada rua, às dezenas e centenas de milhares, enfrentando a polícia e o gás lacrimogéneo, até derrotarem a polícia de Mubarak, expulsando-a da cidade. Tal significa que as estratégias de participação e de confrontação nas ruas foram diferentes consoante o local. O mesmo se pode dizer das caraterísticas organizativas dos diversos atores sociais egípcios, incluindo os trabalhadores e os seus novos sindicatos e comités.

É difícil, porém, negar a participação dos trabalhadores na revolta egípcia, principalmente se se considerar que quase 15 milhões de pessoas vieram para a rua reivindicar 'Liberdade, dignidade e justiça social'.

Com efeito, os trabalhadores não só participaram nos protestos de rua, quer a título individual, quer em pequenos grupos, como também - e isso foi o mais importante - lograram dar a última machadada no governo de Mubarak, já que as greves que empreenderam no início de fevereiro de 2011, durante a semana final de Mubarak, contribuíram para desequilibrar a balança (quando reinava a incerteza quanto ao desfecho dos protestos em massa) no confronto entre as forças revolucionárias e contrarrevolucionárias no terreno. Estas greves estratégicas acabariam por se revelar cruciais para o êxito da revolta.

Acresce que, durante os dias de revolta popular, os trabalhadores foram capazes de juntar forças e criar a Federação Egípcia de Sindicatos Independentes (EFITU). A primeira iniciativa revolucionária concreta foi, assim, a federação dos sindicatos independentes, ou seja, uma organização dos trabalhadores. Foi muito significativo o anúncio da sua criação em 30 de janeiro de 2011, numa conferência de imprensa realizada na Praça Tahrir, no Cairo, com milhares de manifestantes a servir de moldura.

\section{Conclusões: e agora?}

O que este artigo, ainda que sem versar propriamente todas as questões importantes suscitadas a este propósito, pretendeu demonstrar é que a revolta egípcia de 2011 não surgiu num vácuo. Aproximou-se mais de uma reação em cadeia na sequência da revolta do pão, da luta pelos direitos cívicos e políticos, dos protestos em solidariedade com a intifada palestiniana, das manifestações contra a repressão estatal e a guerra no Iraque, e - mais 
importante - das muitas lutas dos trabalhadores. Como bem salientou o jornalista egípcio Hossam El-Hamalawy (2011), “A revolta iniciada em 25 de janeiro de 2011 foi o resultado de um longo processo em que o muro dos medos se foi esboroando, pedaço a pedaço" (The Guardian, 02.02.2011). Tal não quer dizer, no entanto, que a revolta egípcia não representa uma rutura na continuidade histórica; pelo contrário, trata-se claramente de uma rutura, mas que não se deve confundir com as condições para que a sua ocorrência se tornasse possível. Savas colocou corretamente a questão ao escrever:

Se o Acontecimento revolucionário é arrancado às circunstâncias que o tornaram possível, quer dizer, à sua base material ou "lugar do acontecer" [...] com todos os seus elementos e mobilização, então assemelhar-se-á a um milagre metafísico caído do céu. (2011: 422)

Apesar disso, o termo 'revolução', largamente utilizado para referir os recentes levantamentos árabes (e também egípcios), suscitou muita discussão entre estudiosos e comentaristas. O conceito de 'revolução' assume, como se sabe, diferentes sentidos consoante o contexto histórico e sociopolítico: existe revolução só quando um governo é derrubado a partir de baixo, ou tem a revolução mais a ver com transformações profundas nas instituições políticas e nas estruturas sociais? A questão é bastante complexa, mas o presente artigo irá atalhar dizendo que concorda com Gilbert Achcar quando este afirma que, independentemente daquilo que chamamos à agitação árabe e egípcia, há que vê-la como o ato inicial de um processo revolucionário de longo prazo na região, porquanto

[A] revolta imensa iniciada no dia 25 de janeiro de 2011 representa um irromper das massas na cena política que não tem precedente na longuíssima história da terra das pirâmides. Daí não subsistir a mínima dúvida de que ela pôs em movimento toda uma dinâmica revolucionária. É ainda demasiado cedo para nos pronunciarmos sobre as consequências. Os resultados mais radicais do golpe de 1952 só foram visíveis passados muitos anos. Seria bom ter isto em mente. (2013: 15)

Desde o seu início que o movimento dos trabalhadores egípcios constituiu, como constitui ainda, uma das mais importantes subjetividades deste processo revolucionário. Não obstante os trabalhadores não terem figurado nos títulos de capa dedicados às manifestações de massa de janeiro e fevereiro de 2011, o combate por eles travado nos locais de trabalho e nas ruas ao longo da última década foi o que tornou possível o Acontecimento 
revolucionário, quer dizer, a queda do governo de Mubarak. Dia após dia, as greves e os combates travados pelos trabalhadores ao longo de muitos anos conseguiram deslegitimar o regime ditatorial, fomentando uma cultura de protesto entre as classes subalternas e nos movimentos de juventude e feminista. Atente-se nas palavras de Khaled Ali, o destacado ativista dos direitos laborais, em entrevista ao Democracy Now!:

De 2004 a 2011, os trabalhadores lançaram e mantiveram com êxito a maior vaga de mobilizações de cariz laboral a que este país já assistiu. Foram os trabalhadores quem, ao longo dos últimos anos, fez cair as estruturas deste regime. São eles quem vem lutando, no terreno, por uma organização independente, a eles se devendo a criação do primeiro sindicato egípcio efetivamente independente. E foram eles quem insistiu no direito a ter sindicatos pluralistas, em vez de sindicatos onde apenas se amontoam apoiantes do governo. Foram eles quem trouxe as suas queixas para a rua. (Democracy Now!, 2011)

As greves e demais ações coletivas não pararam depois da demissão de Mubarak e do subsequente afastamento de Morsi, nem depois do golpe militar de 2013. Durante a escrita deste texto, e não obstante a dura repressão por parte do exército e da polícia a seguir ao golpe militar - ainda que seja de referir que a repressão estatal parece agora principalmente dirigida contra os membros e simpatizantes da Irmandade Muçulmana -, milhares de trabalhadores egípcios encontram-se em greve, exigindo melhores condições de trabalho, o aumento do salário mínimo e, facto que não constitui surpresa, o cumprimento das promessas da revolução. Eis o que saiu no Daily News Egypt há apenas alguns dias:

No passado domingo um número de operários da Companhia de Fiação e Tecelagem de Algodão de Mahalla calculado em 20000 prosseguiu com a sua greve de oito dias, exigindo salários em atraso, a demissão do presidente da empresa, Abdel-Alim Hassan, e a substituição do comissário Abdel Fattah al-Zoghby. [...] Aos operários da Companhia de Fiação e Tecelagem de Algodão juntaram-se, no domingo, milhares de trabalhadores da cidade de Kafr Al-Dawar, que se manifestaram em solidariedade com os operários de Mahalla. Segundo o Centro Egípcio para os Direitos Sociais e Económicos (ECESR), os trabalhadores de Kafr Al-Dawar reivindicam também a aplicação, aos trabalhadores das empresas do Estado, do salário mínimo já aprovado pelo novo governo. [...]

'Esperamos que todos os meios de comunicação social ajam com honestidade, mostrando-se capazes de transmitir a nossa mensagem ao povo egípcio', lia-se num 
comunicado à imprensa da autoria dos trabalhadores de Mahalla, que acrescentava que os trabalhadores 'exigem justiça não apenas para si, mas para todos os trabalhadores egípcios’. (Omar, 2014 - Daily News Egypt, 17.02.2014)

É sobejamente sabido que o Egito é um país fulcral na zona do Mediterrâneo e Médio Oriente. Como salientam El-Mahdi e Marfleet, "a sua influência económica, política e social está para toda esta região como a do Brasil está para a América do Sul ou a da Índia para o Sul da Ásia” (2009: 151). O Egito é o país com a maior população e a economia mais produtiva da região, tendo, além disso, uma importantíssima influência político-militar (Hashim, 2011) no chamado 'mundo árabe'. Por isso, o que acontece no Egito tem um impacto profundo no Médio Oriente e, mais genericamente, no Sul Global, "especialmente a partir do momento em que uma nova crise mundial veio conferir nova atualidade às discussões sobre os impactos do neoliberalismo e sobre a eficácia da resistência e alternativas ao modelo do mercado global" (El-Mahdi e Marfleet, 2009: 151).

Com as lutas que vêm travando, os trabalhadores egípcios estão a mostrar ao mundo que a revolta ocorrida no seu país "não foi só contra indivíduos corruptos que impedem o capitalismo de funcionar devidamente" (Maher, 2011: 41). Não há dúvida de que as massas de manifestantes que em 2011 saíram à rua desejavam liberdade e reformas democráticas, mas os trabalhadores e os pobres também vieram pedir justiça social e a redistribuição da riqueza do país, após 30 anos de privatizações, depauperamento e políticas neoliberais. ${ }^{2}$ Deste ponto de vista, a participação dos trabalhadores egípcios na revolta de 2011 também deve ser considerada uma resposta de classe à reestruturação económica neoliberal. Ignorar estes aspetos seria não compreender as raízes da revolta em massa vivida no Egito e aquilo que verdadeiramente a desencadeou. Além disso, não deve haver equívocos sobre a natureza socialmente informe da revolta, pois ela não é resultante de

um amálgama de elementos díspares, modernos e tradicionais, numa qualquer relação de equilíbrio. Ela é, antes, a expressão do desenvolvimento paralelo e desigual de um conjunto de contradições "contemporâneas" e "não contemporâneas" (para empregar a própria noção dialética de Ernst Bloch), em que o moderno - e não o tradicional -, ou seja, em que a contradição contemporânea entre capital e trabalho,

\footnotetext{
${ }^{2}$ Calcula-se que quase $40 \%$ da população do Egito vive abaixo do limiar de pobreza, que se situa em US $\$ 2$ por dia, havendo contudo estudiosos que sustentam que, na sequência das reformas neoliberais, os índices de pobreza se encontram ainda mais abaixo do que aquilo que é oficialmente noticiado (Bush, 2004; Sabry, 2010).
} 
a nível global e local - e não as contradições não contemporâneas entre elementos anacrónicos - constitui, em última análise, o eixo determinante desse tecido complexo que são as relações sociais. (Savas, 2011: 423)

A 'primavera' do povo egípcio (e árabe) parece representar, assim, um 'novo despertar' (al-nahda) a Sul. Mas serão os movimentos em curso no Egito, e em especial o movimento dos trabalhadores, capazes de atingir os seus objetivos, de maneira a resistir à dura repressão militar e ao atual sistema económico globalizado e financeirizado, tornando-se, simultaneamente, um modelo de resistência ao mercado global e à injustiça social?

Talvez ninguém o consiga prever neste momento. Mas o Egito continua vibrante, e tudo indica que há ainda muito para ver e esperar no futuro próximo.

Tradução de João Paulo Moreira

Recebido a 22.09.2013

Aprovado para publicação a 30.03.2014

\section{Referências bibliográficas}

Acedo, Clementina (2011), "Achievements and Challenges of Higher Education in Arab Countries", Prospects, 41. Consultado a 05.01.2012, em http://rd.springer. com/article/10.1007/s11125-011-9194-6/fulltext.html.

Achcar, Gilbert (2013), The People Want. A Radical Exploration of the Arab Uprising. Berkeley/Los Angeles/London: University of California Press.

Abram Online (2012a), "Egypt has Quarter of Arab World's Facebook Users: Report", jornal Abram Online, 18.07.2012. Consultado a 18.07.2012, em http://english.ahram. org.eg/NewsContent/3/12/48064/Business/Economy/Egypt-has-quarter-of-Arab-worlds-Facebook-users-Re.aspx.

Abram Online (2012b), "Egyptian Labour Movement Accuses Morsi of Betrayal", jornal Ahram Online, 08.10.2012. Consultado a 08.10.2012, em http://english.ahram.org. eg/NewsContent/1/140/55075/Egypt/Firstdays/Egyptian-labour-movement-accuses-Morsi-of-betrayal.aspx.

Al-Din Arafat, Alaa (2009), The Mubarak Leadership and Future of Democracy in Egypt. New York: Palgrave Macmillan.

Alexander, Anne (2012a), "Egypt's Strikers Defy Crackdown and Win Concessions from Regime", jornal Socialist Worker, 24.07.2012. Consultado a 24.07.2012, em http://www.socialistworker.co.uk/art.php?id=29194. 
Alexander, Anne (2012b), “The Egyptian Workers' Movement and the 25 January Revolution”, Intercol.net, 09.01.2012. Consultado a 09.01.2012, em http://www. intercoll.net/bdf/en/corpus_document/fiche-document-61.html.

Al-Sayyid, Mustapha Kamel (2009), "Kefaya at a Turning Point", in Nicholas Hopkins (org.), Political and Social Protest in Egypt. Cairo Papers in Social Science, Cairo: American University in Cairo Press, 45-59.

Amin, Samir (2011), "An Arab Springtime? ”, Monthly Review, 63(5), 8-28.

Antunes, Ricardo (2013), "The Working Class Today: The New Form of Being of the Class Who Lives from its Labour", Works of the World. International Journal on Strikes and Social Conflicts, 1(2), 7-18.

Ashraf, Fady (2013), "Year in review 2013 - Workers hold 2,486 protests", jornal Daily News Egypt, 31.12.2013. Consultado a 07.05.2014, em http://www.dailynewsegypt. com/2013/12/31/year-in-review-2013-workers-hold-2486-protests/.

Atef, Mohamed (2012), “The Egyptian revolution: Mahalla is leading again”, Counterfire [Online], 15.07.2012. Consultado a 16.07.2012, em http://www.counterfire.org/index. $\mathrm{php} /$ articles/international/15901-the-egyptian-revolution-mahalla-is-leading-again.

Beinin, Joel (1993), "Will the Real Egyptian Working Class Please Stand Up?”, in Zachary Lockman (org.), Workers and Working Class in the Middle East: Struggles, Histories, Historiographies. Albany, New York: State University of New York, 247-270.

Beinin, Joel (2009), “Workers' Struggles Under 'Socialism' and Neoliberalism”, in Rabab El-Mahdi; Philip Marfleet (orgs.), Egypt. Moment of Change. Cairo: The American University in Cairo Press, 68-86.

Beinin, Joel (2011), “A Workers' Social Movement on the Margin of the Global Neoliberal Order, Egypt 2004-2009”, in Joel Beinin; Frédéric Vairel (orgs.), Social Movements, Mobilization, and Contestation in the Middle East and North Africa. Stanford: Stanford University Press, 181-201.

Beinin, Joel (2012), “The Rise of Egypt's Workers”, The Carnegie Papers [Online], 28.06.2012. Consultado a 10.09.2012, em http://carnegieendowment.org/2012/ 06/28/rise-of-egypt-s-workers/coh8.

Beinin, Joel (2013), "All Unionized and Nowhere to Go", The Carnegie Papers [Online], 08.01.2013. Consultado a 04.02.2013, em http://carnegieendowment. org/2013/01/08/all-unionized-and-nowhere-to-go/f04r.

Beinin, Joel; Vairel, Frédéric (2011a), "The Middle East and North Africa: Beyond Classical Social Movement Theory”, in Joel Beinin; Frédéric Vairel (orgs.), Social Movements, Mobilization, and Contestation in the Middle East and North Africa. Stanford: Stanford University Press, 1-26.

Beinin, Joel; Vairel, Frédéric (2011b), "Afterword: Popular Uprisings in Tunisia and Egypt”, in Joel Beinin; Frédéric Vairel (orgs.), Social Movements, Mobilization, and Contestation in the Middle East and North Africa. Stanford: Stanford University Press, 237-254. 
Bottazzi, Laura; Hamaui, Rony (2011), "I veri perché della rivoluzione egiziana”, Lavoce. info [Online], 08.02.2011. Consultado a 08.02.2014, em http://archivio.lavoce.info/ articoli/pagina1002142.html.

Bush, Ray (2004), "Poverty and Neo-Liberal Bias in the Middle East and North Africa", Development and Change, 35(4), 673-695.

CAPMAS (2011), The Statistical Yearbook. Cairo: Central Agency for Public Mobilisation and Statistics (CAPMAS).

Castells, Manuel (1996), The Rise of the Network Society. Cambridge, MA: Blackwell.

Castells, Manuel (2009), Communication Power. New York: Oxford University Press.

Castells, Manuel (2011), Interview. Consultado a 28.06.2012, em http://globalsociology. com/2011/02/07/the-sociology-elders-on-the-social-movements-in-tunisia-and-egypt/

Dabashi, Hamid (2012), The Arab Spring: The End of Postcolonialism. London/New York: Zed Books.

Democracy Now! (2011), “Egyptian Uprising Fueled by Striking Workers Across Nation”, Interview with Khaled Ali,Democracy Now! 18.02.2011. Consultadoa29.10.2012, em http:// www.democracynow.org/2011/2/18/egyptian_uprising_fueled_by_striking_workers.

Dixon, Marion (2011), “An Arab Spring”, Review of African Political Economy, 38(128), 309-316.

Egyptian Solidarity Centre (2010), The Struggle for Worker Rights in Egypt: A Report by the Solidarity Centre. Consultado a 04.04.2012, em http://www.solidaritycenter. org/files/pubs_egypt_wr.pdf.

El-Hamalawy, Hossam (2011), "Egypt's Revolution Has Been 10 Years in the Making”, jornal The Guardian, 02.03.2011. Consultado a 02.02.2011, em http://www.theguardian.com/commentisfree/2011/mar/02/egypt-revolution-mubarak-wall-of-fear

El-Mahdi, Rabab (2011a), “Orientalising the Egyptian Uprising”, Jadaliyya, 11.04.2011. Consultado a 11.04.2011, em http://www.jadaliyya.com/pages/index/1214/ orientalising-the-egyptian-uprising.

El-Mahdi, Rabab (2011b), "Labour Protests in Egypt: Causes and Meanings", Review of African Political Economy, 38(129), 387-402.

El-Mahdi, Rabab; Marfleet, Philip (2009), "Conclusion: What's Next?", in Rabab El-Mahdi; Philip Marfleet (orgs.), Egypt: Moment of Change. Cairo: The American University in Cairo Press, 151-155.

El Shafei, Omar (1995), "Workers, Trade Unions, and the State in Egypt: 1984-1989”, Cairo Papers in Social Science, 18(2), 1-43.

Friedman, Thomas (2011a), "This is Just the Start", jornal The New York Times, 01.03.2011. Consultado a 04.02.2012, em http://www.nytimes.com/2011/03/02/ opinion/02friedman.html.

Friedman, Thomas (2011b), "I am a man", jornal The New York Times, 14.05.2011. Consultado a 14.05.2011, em http://www.nytimes.com/2011/05/15/opinion/ 15 friedman.html. 
Haass, Richard (2011), "Reflection on the Revolution in Egypt", in Council on Foreign Relations (org.), The New Arab Revolt. New York: Council on Foreign Relations, 115-119. Hall, John (1997), Reworking Class. Ithaca, New York: Cornell University Press.

Hashim, Ahmed (2011), "The Egyptian Military, Part two: From Mubarak Onward", Middle East Policy, XVIII(4), 106-128.

Hinnebusch, Raymond (1985), Egyptian Politics Under Sadat. Cambridge: Cambridge University Press.

Horovitz, David (2011), “A Mass Expression of Outrage Against Injustice”, jornal The Jerusalem Post, 25.02.2011. Consultado a 25.02.2011, em http://www.jpost. com/Opinion/Columnists/Article.aspx?id=209770.

Howard, Philip (2011), The Digital Origins of Dictatorship and Democracy: Information Technology and Political Islam. Oxford: Oxford University Press.

Khondker, Habibul Haque (2011), "Role of the New Media in the Arab Spring", Globalizations, 8(5), 675-679.

Levinson, Charles (2005), “Egypt's Growing Blogger Community Pushes Limit of Dissent”, jornal The Christian Science Monitor, 24.08.2005. Consultado a 24.09.2012, em http://www.csmonitor.com/2005/0824/p07s01-wome.html.

Lindsey, Ursula (2012), "Revolution and Counterrevolution in the Egyptian Media", in Jeannie Sowers; Chris Toensing (orgs.), The Journey to Tabrir: Revolution, Protest, and Social Change in Egypt. London/New York: Verso, 53-63.

Maher, Stephen (2011), “The Political Economy of the Egyptian Uprising”, Montbly Review, 63(6), 32-45.

Marshall, Gordon (1997), Repositioning Class: Social Inequality in Industrial Societies. London: Sage.

Munif, Yasser (2013), "The Arab Revolts: The Old is Dying and the New Cannot Be Born”, Rethinking Marxism: A Journal of Economics, Culture E Society, 25(2), 202-217.

Omar, Ali (2014), “Mahalla Textile Workers' Strike Enters the Eighth Day”, Daily News Egypt, 17.02.2014. Consultado a 17.02.2014, em http://www.dailynewsegypt. com/2014/02/17/mahalla-textile-workers-strike-enters-eighth-day.

Poster, Mark (1995), "Cyberdemocracy: Internet and the Public Sphere”. Consultado a 23.10.2011, em http://www.humanities.uci.edu/mposter/writings/democ.html.

Posusney, Marsha Pripstein (1993), "Collective Action and Workers' Consciousness in Contemporary Egypt”, in Zachary Lockman (org.), Workers and Working Classes in the Middle East: Struggles, Histories, Historiographies. Albany, New York: State University of New York Press, 211-246.

Rasha, Abdulla (2011), "The Revolution Will Be Tweeted: The Story of Digital Activism in Egypt", The Cairo Review of Global Affairs, 3, 41-50.

Sabry, Sarah (2010), "How Poverty is Underestimated in Greater Cairo, Egypt", Environment and Urbanization, 22, 523-541. 
Savas, Michael-Matsas (2011), "The Arab Spring: The Revolution at the Doors of Europe”, Critique: Journal of Socialist Theory, 39(3), 421-432.

Schemm, Paul (2012), "Activist Dissent and Anti-War Protest in Egypt”, in Jeannie Sowers; Chris Toensing (orgs.), The Journey to Tahrir: Revolution, Protest, and Social Change in Egypt. London/New York: Verso, 85-92.

Shihade, Magide; Flesher, Fominaya, Cristina; Cox, Laurence (2012), "The Season of Revolution: The Arab Spring and European Mobilization”, Interface, 4(1), May, 1-16. Consultado a 15.09.2012, em http://www.interfacejournal.net/wordpress/ wp-content/uploads/2012/05/Issue-4-1-Full-PDF.pdf.

Teti, Andrea; Gervasio, Gennaro (2012), “After Mubarak, before Transition: The Challenges for Egypt's Democratic Opposition”, Interface, 4(1), May, 102-112. Consultado a 15.09.2012, em http://www.interfacejournal.net/wordpress/wp-content/uploads/2012/05/Issue-4-1-Full-PDF.pdf.

Trumka, Richard (2011), "Foreword”, in Egyptian Solidarity Centre (org.), Struggle for Worker Rights in Egypt. Consultado a 06.06.2011, em http://www.solidaritycenter. org/files/pubs_egypt_wr.pdf.

World Bank (2007), Doing Business in Egypt 2008. Washington DC: World Bank. Consultado a 08.05.2014, em http://www.doingbusiness.org/ /media/GIAWB/ Doing \%20Business/Documents/Annual-Reports/English/DB08-FullReport.pdf. Wright, Erik Olin (2007), Class Counts. Cambridge: Cambridge University Press. 
